\title{
MENINGKATKAN KUALITAS SUMBER DAYA MANUSIA (SDM) NELAYAN MELALUI MANAJEMEN SDM YANG TERTATA, TERKOORDINASI DAN MEMANFAATKAN WISATA PADA KELURAHAN PULAU PARI KECAMATAN KEPULAUAN SERIBU SELATAN
}

\author{
Yhonanda Harsono $^{1}$, Santi Octavianti ${ }^{2}$, Dewi Lestari ${ }^{3}$, Muhammad Mansyur ${ }^{4}$, Heri \\ Priyanto 5 \\ Universitas Pamulang \\ Email: yhonanda2906@gmail.com
}

\begin{abstract}
This PKM takes the object of service, are the fishermen who are residents of $R T 001 R W 004$ pari island south seribu island. Community service partners in this PKM Management RT 001/004. The problem that was taken came from the productivity of the fishermen in Pari Island sub-district of the South Thousand Islands sub-district, the DKI Jakarta Province was still not maximal, Not yet skilled fishermen in Pari Island Village, South Thousand Islands District, DKI Jakarta Province in managing fish catches properly (such as frozen food, food variations, etc.), and There is still a lack of human resource management for fishermen in the Pari Island sub-district of the South Thousand Islands sub-district, DKI Jakarta Province. The Pkm program provided is in the form of seminars on ways to improve and improve the quality of fishermen in Pari Island Village, South Seribu Islands District and training on how to store, process and market the catch of fishermen on Pari Island. In the future, it is hoped that the quality of existing human resources, namely the fishermen of Pulau Pari Village, South Thousand Islands District, can be repaired and improved so that they can contribute more to the Pulau Pari Village, Kepulauan Seribu Subdistrict, and Pari Island fishermen have entrepreneurial knowledge who have business ethics, handle customer complaints and how to market good products in the South, besides that future service is expected to provide more applicable training. so that it can provide them with provisions in facing competition and seeing opportunities in the future.
\end{abstract}

Keywords: fishermen, pari island, human resources, seminars and training

\begin{abstract}
Abstrak
PKM ini mengambil objek pengabdian yaitu nelayan yang merupakan warga dari RT 001 RW 004 Pulau Pari Kepualauan Seribu Selatan. Mitra pengabdian pada PKM ini Pengurus RT 001/004. Masalah yang diambil berasal dari produktivitas nelayan kelurahan Pulau Pari kecamatan kepulauan seribu selatan, Provinsi DKI Jakarta masih belum maksimal
\end{abstract}


Belum terampilnya nelayan kelurahan Pulau Pari kecamatan kepulauan seribu selatan, Provinsi DKI Jakarta pengelolaan hasil tangkapan ikan dengan baik (seperti frozen food, variasi makanan dll.), dan Masih kurangnya pengelolaaan Sumber Daya Manusia bagi nelayan kelurahan Pulau Pari kecamatan kepulauan seribu selatan, Provinsi DKI Jakarta. Program Pkm yang diberikan adalah berupa seminar mengenai cara - cara meningkatkan dan memperbaiki kualitas nelayan Kelurahan Pulau Pari Kecamatan Kepulauan Seribu Selatan Dan pelatihan cara -cara menyimpan, mengolah dan memasarkan hasil tangkapan nelayan di Pulau Pari Kedepan diharapkan agar kualitas sumber daya manusia yang ada yaitu nelayan Kelurahan Pulau Pari Kecamatan Kepulauan Seribu Selatan dapat perbaiki dan ditingkatkan sehingga bisa memberikan kontribusi lebih kepada Kelurahan Pulau Pari Kecamatan Kepulauan Seribu, dan nelayan pulau pari memilikipengetahuan berwirausaha yang mempunyai etika bisnis, menangani keluhan pelanggan dan cara memasarkan produk yang baik Selatan, selain itu pengabdian kedepan diharapkan memberikan pelatihan yang lebih aplikatif. sehingga dapat memberi mereka bekal dalam menghadapi persaingan dan melihat peluang di masa yang akan datang.

\section{Kata Kunci : Nelayan, Pulau Pari, SDM, Seminar dan Pelatihan}

\section{A. PENDAHULUAN}

Indonesia adalah negara kepulauan terbesar di dunia dengan wilayah yanh meliputi 17.508 pulau luas lautannya mencapai 5,8 juta $\mathrm{km} 2$ atau $70 \%$ dari luas wilayah Indonesia. Kepulauan Seribu adalah tempat yang menawarkan atraksi dengan suasana bahari yang masih asri, kepuluan seribu tidak berjumlah 1000 tetapi sekitar 110 yang terdiri dari pulau-pulau besar dan pulau-pulau kecil yang bisa digolongkan menjadi 2 jenis yaitu pulau penduduk dan pulau resort, dari 2 jenis pulau tersebut bisa digolongkan kembali pulau-pulau yang menjadi pulau wisata, pulau sejarah, dan pulau konservasi, yang termasuk dalam pulau wisata antara lain. Kepulauan Seribu terbentang dari pulau yang paling dekat yaitu Pulau Ayer sampai dengan sampai dengan pulau yang sangat jauh dari Laut Jawa yaitu Pulau Hantu dan Pulau Sebira. Pemerintahan Kabupaten Administrasi Kepuluan Seribu terbagi menjadi 2 kecamatan dan 6 kelurahan, dua kecamatan itu adalah Kecamatan Kepulauan Seribu Utara dan Kecamatan Kepulauan Seribu Selatan sedangkan untuk kelurahannya adalah Kelurahan Pulau Kelapa, Kelurahan Pulau Harapan, Kelurahan Pulau Panggang, Kelurahan Pulau Tidung, Kelurahan Pulau Pari dan Kelurahan Untung Jawa.

Dengan banyaknya minat pengunjung untuk berkunjung ke pulau Pari dapat meningkatkan ekonomi masyarakat khususnya nelayan dengan dibekalkan kemampuan untuk berusaha mengelola hasil tangkapan untuk diproses dan dijadikan buah tangan wisatawan. Dampak ekonomi langsung dari pengeluaran wisatawan yang dirasakan langsung oleh para nelayan. Pendapatan pemilik dari unit usaha di Pulau Pari, unit usaha yang ada di Pulau Pari merupakan pihak penerima dampak langsung dari pengeluaran wisatawan. Kegiatan wisata bahari di Pulau Pari telah menciptakan aktivitas ekonomi dari aliran uang yang berasal dari wisatawan. Aliran uang tersebut memberikan dampak ekonomi dari transaksi wisatawan dengan unit-unit usaha pengolahan ikan serta para nelayan di Pulau Pari

Nelayan yang secara turun-temurun telah menjadikan kegiatan menangkap ikan di laut sebagai mata pencaharian utama, masih sulit mengembangkan diri untuk menjadi nelayan yang lebih maju. Nelayan berpendidikan rendah, bahkan putus sekolah. Kesempatan yang 
diberikan oleh pemerintah diperkirakan masih kurang atau tidak sesuai dengan kebutuhan usaha nelayan untuk berkembang menjadi nelayan yang lebih maju. Waktu yang lebih banyak dihabiskan di laut, menyebabkan nelayan mengalami kesulitan belajar secara normal seperti warga masyarakat lainnya yang bekerja di darat. Akibatnya nelayan kehilangan banyak waktu untuk memikirkan dan melakukan berbagai hal untuk meningkatkan mutu kehidupannya dan mutu kehidupan keluarganya. Untuk memecahkan persoalan-persoalan yang dihadapi nelayan, dan agar nelayan dapat bangkit menjadi nelayan yang lebih maju, nelayan perlu meningkatkan mutu sumber daya manusianya. Ditinjau dari konsep mutu, semakin tinggi mutu sumber daya manusia yang dimiliki nelayan, maka akan semakin besar kemampuan nelayan memenuhi kebutuhan pelanggan-pelanggannya. Misalnya saja, untuk dapat memenuhi kebutuhan pelanggan internal nelayan, yaitu dirinya sendiri dan keluarganya, nelayan membutuhkan penghasilan yang memadai.

Nelayan dianggap perlu membenahi sistem usahanya, dan memiliki kompetensi yang sesuai untuk dapat memanfaatkan peluang usaha yang terbuka. Nelayan tradisional harus menjadi nelayan yang maju dalam menjalankan usahanya, sehingga dapat memainkan peran aktif dan ikut menentukan dalam pasar perikanan, baik di dalam negeri maupun di luar negeri. Dengan sistem usaha yang tepat dan kesempatan yang terbuka luas serta kompetensi yang memadai, diharapkan nelayan dapat menjalankan usahanya dengan baik, sehingga mampu memenuhi kebutuhan konsumennya. Kompetensi nelayan yang selalu ditingkatkan dan dikembangkan diharapkan dapat berakibat makimeningkatnya mutu sumber daya manusia nelayan. Namun, meningkatnya kompetensi nelayan perlu didukung dengan kesempatan berusaha, dan sistem usaha yang tepat bagi nelayan.

Solusi yang tepat untuk mengatasi permasalahan tersebut adalah dengan memberikan seminar, penyuluhan atau pelatihan yang perlu di lakukan secara berkelanjutan sehingga dapat memberi mereka bekal dalam menghadapi persaingan dan melihat peluang di masa yang akan datang, di samping itu memberi mereka pengetahuan berwirausaha yang mempunyai etika bisnis, menangani keluhan pelanggan dan cara memasarkan produk yang baik.

\section{B. METODE PELAKSANAAN}

Kerangka pemecahan masalah yang dilakukan dalam pengabdian pada masyarakat di nelayan di Kelurahan Pulau pari Kecamatan Kepulauan Seribu Selatan dimulai dengan melakukan analisis situasi meliputi kondisi riil yang terjadi di obyek pengabdian yang bersumber dari Pengurus RT 001 RW 04 Kelurahan Pulau pari Kecamatan Kepulauan Seribu Selatan selanjutnya menelaah dan menetapkan pendekatan pengabdian pada masyarakat sesuai kebutuhan. Hal ini dilakukan agar program pengabdian memiliki daya rubah yang besar sekaligus Meningkatkan Kualitas Sumber Daya Manusia (SDM) Nelayan Melalui Manajemen SDM yang tertata, Terkoordinasi. Pendekatan terbagi menjadi dua yang pertama menitikberatkan kepada Seminar dengan metode tanya jawab dan solusi pemecahan masalah yang selama ini menjadi masalah pada nelayan yang ada di Kelurahan Pulau Pari Kecamatan Kepulauan Seribu Selatan dan yang kedua adalah berbentuk Pelatihan yang lebih menitikberatkan meningkatkan dan memperbaiki kualitas SDM nelayan Kelurahan Pulau Pari Kecamatan Kepulauan Seribu Selatan dalam kegiatan pengolahan dan pemasarah hasil tangkapan ikannya: 


\section{HASIL DAN PEMBAHASAN}

\section{Letak Geografi Lokasi Pengabdian}

Berdasarkan Surat keputusan Gubernur Kepala Daerah Tingkat I DKI Jakarta Nomor 1914 tahun 1989 menetapkan Pulau pari dan enam buah pulau lainnya yang ada di sekitar Pulau Pari termasuk ke dalam Gugusan Pulau pari. Dengan berlakunya UndangUndang Otonomi Daerah, maka berdasarkan Surat keputusan Gubernur Propinsi DKI Jakarta Nomor 1986/2000 tanggal 27 Juli 2000 tentang Pemecahan, Pembentukan, Penetapan, batas dan Luas Kecamatan Pulau Seribu, maka Pulau Pari dimasukkan ke dalam lingkungan Kelurahan Pulau Pari yang berkedudukan di Pulau Lancang, dalam Kecamatan Kepulauan Seribu Selatan yang berkedudukan di Pulau Tidung di bawah pemerintahan Darerah Tingkat II Administrasi Kepulauan Seribu yang berkedudukan di Pulau Pramuka. Kelurahan Pulau pari terdiri dari sepuluh buah pulau, tujuh buah pulau berada di Gugusan Pulau pari dan tiga buah pulau berada di gugusan Pulau lancing. Gugusan Pulau Pari memiliki luas daratan seluas 50,62 ha atau sekitar 53,52\% dari luas daratan Kelurahan Pulau Pari yaitu seluas 96,57 ha. Pulau pari terletak pada lintang 5050'00' LS dan 5052'30' LS dan bujur 106 $34^{\prime} 30^{\prime}$ BT dan $106^{0} 38^{\prime} 28^{\prime}$, berada di sebelah selatan alur dalam dari Paparan Sunda (sunda self) yang merupakan alur lalu lintas kapal menuju Selat Sunda dari Jakarta. Sebelah utara alur tersebut berbatasan dengan Pulau Payung dan Pulau Tidung. Pulau Pari berjarak kurang lebih 35 km dari Jakarta. Pulau Pari berada pada ketinggian 0-1 meter diatas permukaan laut dengan bentuk permukaan tanah $100 \%$ datar, tempertut harian maksimal $30^{\circ} \mathrm{C}$ dan rata- rata minimum $23^{\circ} \mathrm{C}$ dengan variasi tahunananya yang kecil. Arus juga berpengaruh terhadap perairan sekitar Pulau pari yaitu arus timur dan arus barat, sedangkan untuk reliefnya terutama dipengaruhi oleh arus pasang surut.

\section{Tahap Persiapan Pelaksanaan Kegiatan}

Kami melakukan survey untuk memastikan kondisi nelayan di Kelurahan Pulau pari Kecamatan Kepulauan Seribu Selatan. Data ini diperlukan untuk menyusun daftar bantuan yang hendak diberikan sekaligus menjadi pertimbangan didalam keikutsertaan dalam kegiatan seninar dan pelatihan. Setelah melakuakn survey maka tahap selanjutnya menentukan lokasi pelaksanaan dan penentuan sasaran yang benar-benar membutuhkan seminar dan pelatihan. Penetapan lokasi ini berguna agar penyelenggaraan kegiatan bisa memudahkan nelayan di Kelurahan Pulau pari Kecamatan Kepulauan Seribu Selatan untuk datang pada lokasi kegiatan.

\section{Tahap Pelaksanaan Kegiatan}

Pada Tahap ini kami melaksanakan kegiatan Seminar. Dalam acara seminar di isi oleh seluruh dosen baik ketua maupun anggota peserta Pengabdian Kepada Masyarkat ( PKM ) materi yang di bahas tentang cara - cara meningkatkan dan memperbaiki kualitas nelayan Kelurahan Pulau Pari Kecamatan Kepulauan Seribu Selatan, kegiatan seminar ini di harapkan mampu memberi solusi bagi nelayan Kelurahan Pulau Pari Kecamatan Kepulauan Seribu Selatan. Kegiatan ini dilaksanakan di aula Kelurahan Pulau Pari Kecamatan Kepulauan Seribu Selatan, berlangsung dari pukul 13.00 Wib sampai dengan 16.30 Wib. Peserta sangat antusias dalam mengikuti kegiatan seminar. Peserta mampu memaksimalkan kegiatan ini karena kegiatan di lakukan dengan metode tanya jawab dan solusi pemecahan masalah yang selama ini menjadi masalah pada nelayan yang ada di Kelurahan Pulau Pari Kecamatan Kepulauan Seribu Selatan Selain Seinar, dilakukan juga Pelatihan bagi Nelayan yang ada di Pulau Pari. Pelatihan yang di lakukan adalah pelatihan 
cara -cara menyimpan, mengolah dan memasarkan hasil tangkapan nelayan di pulau pari . Kegiatan ini bertujuan meningkatkan dan memperbaiki kualitas SDM nelayan Kelurahan Pulau Pari Kecamatan Kepulauan Seribu Selatan dalam kegiatan pengolahan dan pemasarah hasil tangkapan ikannya. Peserta sangat antusias dalam mengikuti pelatihan yang dibawakan oleh tim dosen Pengabdian Kepada Masyarakat. Kesiapan tim dosen dalam membawakan materi pelatihan membuat peserta aktif mengikuti kegiatan.

\section{KESIMPULAN DAN SARAN}

\section{Kesimpulan}

Kehadiran Pengabdian Kepada Masyarakat dari Unpam dalam membantu anggotanya sangat dirasakan manfaatnya oleh nelayan Pulau Pari sehingga di harapkan akan muncul inovasi - inovasi baru dalam mengolah dan memasarkan serta mengembangkan usaha milik nelayan di Pulau Pari. Pengembangan SDM melalui Seminar, Pelatihan dan Penyuluhan lebih lanjut akan meningkatkan usaha nelayan di Pulau Pari.

\section{Saran}

Guna tercapai tujuan dari pengarahan, seminar, penyuluhan atau pelatihan dan pendampingan nelayan di Pulau Pari ada beberapa saran yang perlu diperbaiki, yakni : (1) Komunikasi disini sangatlah penting karena keberhasilan dalam berkomunikasi antara pengarahan, seminar, penyuluhan atau pelatihan dan pendampingan dengan nelayan, maka akan memudahkan program-program pengarahan, penyuluhan atau pelatihan dan pendampingan dapat berjalan dengan baik. (2) Meningkatkan dan memperbaiki SDM Nelayan di Kelurahan Pulau Pari Kecamatan Kepulauan Seribu Selatan. (3) Perlunya struktur organisasi yang baik agar SDM yang ada di Kelurahan Pulau Pari Kecamatan Kepulauan Seribu Selatan dapat menghadapi persaingan dan melihat peluang di masa yang akan dating. (4) Memberikan pengetahuan berwirausaha yang mempunyai etika bisnis, menangani keluhan pelanggan dan cara memasarkan produk yang baik.

\section{Ucapan Terima Kasih}

Rasa syukur dan suka cita kamu haturkan kepada segenap pihak yang telah mensukseskan kegiatan PKM dengan judul "Meningkatkan Kualitas Sumber Daya Manusia (SDM) Nelayan Melalui Manajemen SDM yang tertata, Terkoordinasi dan Memanfaatkan Wisata pada Kelurahan Pulau Pari Kecamatan Kepulauan Seribu Selatan" kepada:

1. Rektor Dr. H. Dayat Hidayat, M.M, Rektor Universitas Pamulang Tangerang Selatan - Banten.

2. Dr. Ali Maddinsyah, S.E., M.M., selaku Ketua LPPM Universitas Pamulang Tangerang Selatan - Banten.

3. Dr. Kasmad, S.E., M.,M., selaku Ketua Program Studi Manajemen Universitas Pamulang Tangerang Selatan - Banten.

4. Dr. Udin Ahidin, S.E., M.M., C.M.A, Selaku Wakil Program Studi Manajemen Universitas Pamulang Tangerang Selatan - Banten.

5. Drs. Waluyo Jati, M.M., Selaku Sekretaris Program Studi Manajemen Universitas Pamulang Tangerang Selatan - Banten.

6. Edi Mulyana ., selaku Ketua RT 001/004 Kelurahan Pulau Pari Kecamatan Kepulauan Seribu Selatan

7. Mahasiswa Universitas Pamulang yang juga ikut berkontribusi terhadap kelancaran kegiatan PKM. 


\section{DAFTAR PUSTAKA}

Ahmadi. (1988). Panduan Pengajar Buku Ketrampilan Menulis. Jakarta: PPLPTK

Amin Widjaja Tunggal, Manajemen: Suatu Pengantar, (Jakarta: Rineka Cipta 2012), hlm.251

Dedi Mulia. (2004). Alternatif Pengembangan Gugusan Pulau Pari Kepualauan Seribu Sebagai Objek Wisata Eko Bahari di DKI Jakarta, Institut Pertanian Bogor, Institut Pertanian Bogor

Dessler, Gary. (2008). Manajemen Sumber Daya Manusia. Terj.Edisi kesepuluh jilid I bekerjasama dengan Paramita Rahayu. Indonesia: PT. Macanan Jaya Cemerlang.

Dumilah, R., Sunarto, A., Solihin, D., \& Maulida, H. (2020). Pelatihan Pemanfaatan Media Sosial Untuk Promosi Usaha Atau Bisnis Bagi Siswa. DEDIKASI PKM, 1(1), 26-33.

Edy Sutrisno. (2009). Manajemen Sumber Daya Manusia Edisi pertama. Jakarta: Kencana Prenada Media Group;

Gomes, Faustiono Cardoso. (2003). Manajemen Sumberdaya Manusia. Yogyakarta: Penerbit Andi.

Hasibuan, Malayu SP. (2001). Manajemen Sumber Daya Manusia. Edisi revisi.. Bumi Aksara. Jakarta.

\section{Perkasa}

(2002). Manajemen Sumber daya manusia. Jakarta: PT Bumi

Hendrawaty. Dkk, 2006, Bisnis dan Manajemen. Jurnal Ilmiah Berkala Empat Bulanan, ISSN 1411 - 9366 Volume 2 No. 3 Mei 2006. Mei 2015

Mardiana, S., Supriyatna, W., Hasanah, Y. M., Zakaria., \& Indirasari, I. (2010). Optimalisasi Anggaran Keuangan Di Masa Pandemi Pada Desa Cicalengka Kabupaten Pagedangan Tangerang. DEDIKASI PKM. 1(3).

Mondy, R. Wayne. 2008. Manajemen Sumber Daya Manusia. Terj. Edisi kesepuluh jilid I bekerja sama dengan. Penerbit Erlangga. Jakarta: Erlangga

Noe, R. A. 2008. Employee Training and Development. Fourth Edition. NewYork: McGrawHill

Qurbani, D., Mardiana, S., \& Nugroho, R. D. (2020). Meningkatkan Minat Dan Potensi Generasi Milenial Khususnya Siswa-Siswi SMK Darussalam Untuk Memulai Bisnis Online Dengan Sistem Dropship. DEDIKASI PKM. 1 (3).

Seputra. Yulius Eka Agung, (2014), Manajemen dan perilaku Organisasi. Graha Ilmu, Yogyakarta.

Siswanto, (2005), Pengantar Manajemen, Bumi Aksara, Jakarta

Solihin, D., Prasetiyani, D., Sari, A. R., Sugiarti, E., \& Sunardi, D. (2020). PEMANFAATAN BOTOL BEKAS SEBAGAI PENYARING AIR BERSIH SEDERHANA BAGI WARGA DESA CICALENGKA KECAMATAN PAGEDANGAN KABUPATEN TANGERANG. DEDIKASI PKM, 1(3), 98-102.

Tegeh, I Made, dkk. (2013). Seminar Pendidikan. Singaraja: Universitas Pendidikan Ganesha Press. 
Trebbler. Timothy ,. Heyworth. Nicola,. Clarke. Nicholas,. Powell. Timothy,. Hockey, Peter M,. 2014. Managing hospital doctors and their practice: what can we learn about human resource management from non-healthcare organisations, BMC Health Service Research.2014, Vol 14 issue 1, P.566-558.23p. April 2015

Wibowo, Manajemen Kinerja, ed.revisi, (Jakarta: Rajawali pers,2014), hlm.370

Undang-Undang Nomor 7 tahun 2006 tentang Perlindungan dan Pemberdayaan Nelayan, Pembudi daya Ikan dan Petambak Garam

Data Pengunjung Pulau Pari tahun 2019.2019. https://data.jakarta.go.id/dataset/data-jumlahpenumpang-di-wilayah-kepulauan-seribu-tahun-2017, Website Pemerinta Provinsi DKI Jakarta;

Surat Edaran Nomor 3 Tahun 2020 tentang Pencegahan COVID-19 pada Satuan Pendidikan;

Peraturan Gubernur Nomor 27 Tahun 2020 tentang Pedoman PSBB 